\title{
TEM Analysis of Bacterial Colony Biology using Microwave-Assisted Processing and LR White Resin
}

\author{
D.L. Chance *, C.A Jensen, *****, T. J. Reilly ***, and T.P. Mawhinney **** \\ * Departments of Molecular Microbiology \& Immunology and Child Health, University of Missouri, \\ Columbia, MO 65212 \\ ** Electron Microscopy Core Facility, University of Missouri, Columbia, MO 65211 \\ *** Department of Veterinary Pathobiology, University of Missouri, Columbia, MO 65211 \\ **** Departments of Biochemistry and Child Health, University of Missouri, Columbia, MO 65211
}

Transmission electron microscopy (TEM) provides an essential tool for the study of microorganisms in the plant or animal host, and in their native environments. In studies of host-bacterial interactions [1-4], we are focused on features of opportunistic pathogens that may play a role in their virulence. Key to understanding the normal biological functions of biomolecules such as the enzyme acid phosphatase (AcPase) elaborated by many commensal pathogens [2, 4], is the ability to study the expression of these characteristics within the organization of the bacterial colony. For such TEM studies to be feasible, a method must be able to stabilize bacterial colony structure and permit, at the same time, a means to observe the ultrastructural detail of the organisms and also be amenable to immunolabeling and the ability to assay biochemical activities within the colony.

Presented here is such an approach, developed by combining positive attributes of several common techniques for application in culture studies. Clostridium perfringens was grown anaerobically on blood agar, colonies lightly covered with warm $2 \%$ agarose in PBS, and after solidification of the agarose, strips of media with agarose encased colonies were trimmed and processed for TEM employing a microwave-assisted technique [5], and an immunofixative (IF) solution previously described [6], to which was added $0.1 \%$ ruthenium red (RuR). All microwave (MW)-assisted steps in processing were performed under vacuum and on a cooled recirculating water bath for reducing specimen heat generation during MW irradiation. Briefly, samples were fixed in the MW for $1 \mathrm{~min}$ power off, $80 \mathrm{~s}$ of microwave irradiation (MI) at $120 \mathrm{~W}$ power, 3 min power off, and another $40 \mathrm{~s}$ of $\mathrm{MI}$ at $350 \mathrm{~W}$. After rinses outside of the MW, samples were dehydrated through a graded ethanol series, with each step MW-assisted $120 \mathrm{~W}$ for $40 \mathrm{~s}$, and then infiltrated with medium grade LR white resin, MW-assisted at 250W, with 3 min MI per step from absolute EtOH to pure resin. Samples were flat mold embedded and UV polymerized at low temperature $\left(4^{\circ} \mathrm{C}-6^{\circ} \mathrm{C}\right)$. Assays for acid phosphatase $[2,4]$ at either $37^{\circ} \mathrm{C}$ or room temperature employed $1 \mathrm{mM}$ AMP as the substrate in 50 $\mathrm{mM} \mathrm{NaOAc}$ buffer, $\mathrm{pH} 6.0$, and freshly filtered $0.12 \%$ lead nitrate as the phosphate capture agent.

As described in the Figures 1 and 2, microwave assisted processing of immunofixed samples, UV polymerized at low temperature, provided for TEM analysis intact colonies with good bacterial ultrastructure. Use of RuR in the fixative permitted ready identification of the bacterial colonies within the cured resin. MW-assisted processing and low temperature resin polymerization also preserved the enzyme activity assayed for in this study as seen in Figure 2. MW processing provides a convenient means to coordinate harvesting of multiple samples for immunolabeling and biological assays, and is much less technically challenging than cryofixation and cryoultramicrotomy. Application of this, and similar approaches, should greatly facilitate the use of TEM in studies of physical and biochemical interactions between bacteria within colonies and in their host. 
References:

[1] T.P. Mawhinney and D.L. Chance, J. Carb. Chem 13(1994) 825.

[2] D.L Chance et al, J. Microbiol. Met.39(1999) 49.

[3] D.L. Chance et al, Microsc. Microanaly. 10(Suppl 2), 2004.

[4] T.J. Reilly, et al 2005, manuscript in preparation.

[5] K.D. Wendt et al, .J Microscopy 214(2004) 80.

[6] G.N. Gobert et al, Histochem. Cell. Biol 115(2001) 381.

[7] This work was supported by corporate sponsors, the Cystic Fibrosis Association of Missouri, and the Experiment Station Chemical Laboratories of the Univ. of Missouri-Columbia (UM-C); electron microscopy was performed at the Electron Microscopy Core Facility (EMC) of the UM-C. The authors appreciate the valuable insights contributed to this project by Randy Tindall of the EMC.
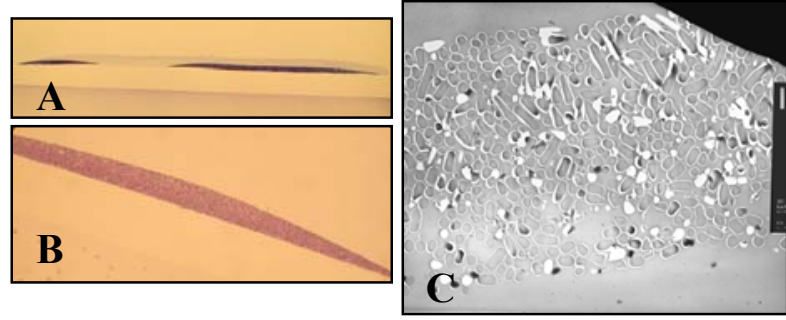

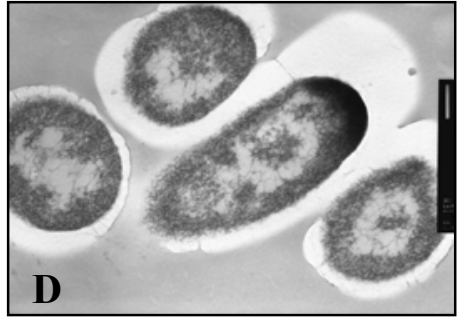

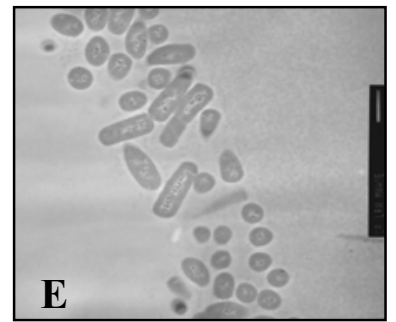

FIG 1. Light and electron micrographs of cross-sectioned immunofixed bacterial colonies preserved in LR white resin with microwave-assisted processing. (A) Colonies as thick sections either stained with toluidine blue (4X), or (B) unstained, reflecting ruthenium red dying during fixation (40X). TEM imaged (C) unstained bacteria within colony (bar $=2 \mu \mathrm{m}$; (D) uranyl acetate/lead citrate (UA/ LC) stained bacteria with ultrastructure preservation, bar $=200 \mathrm{~nm}$; and (E) unstained section with improved imaging of LR white resin embedded colony (reduced resin tearing from around bacteria upon beam exposure) by lightly coating specimen with protein solution prior to imaging, bar $=1 \mu \mathrm{m}$.
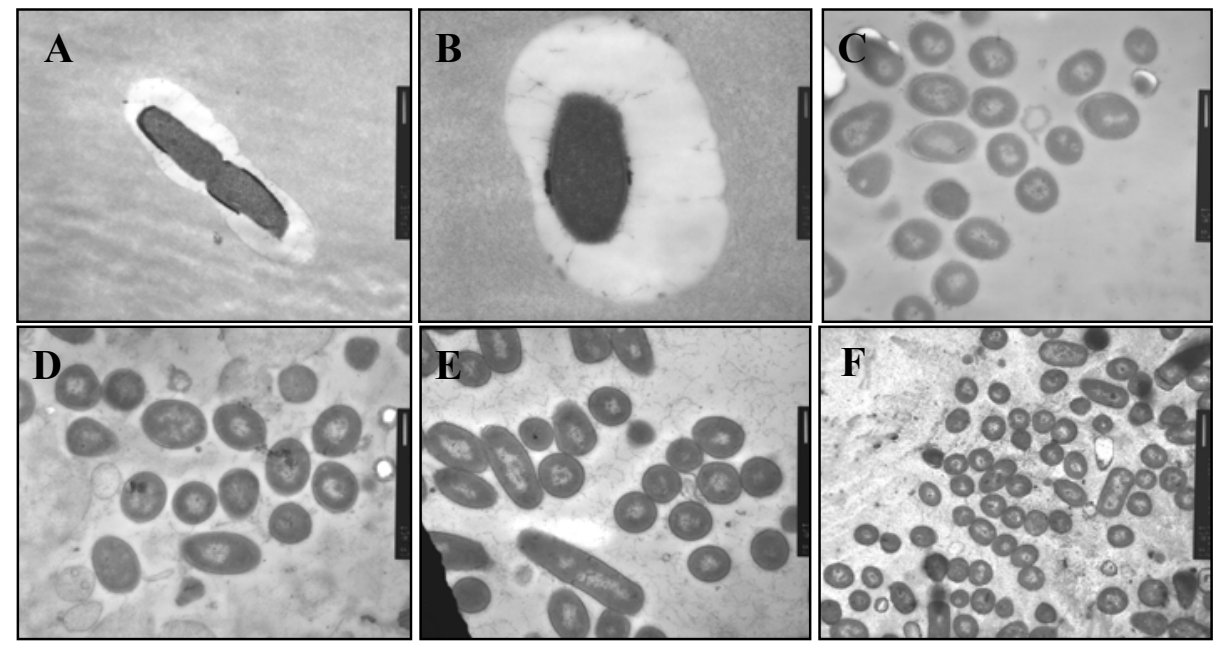

FIG 2. TEM analysis for acid phosphatase activity (indicated by dark precipitate of reaction product with capture agent), from single organisms and bacteria in the context of the colony. Acid phosphatase activity was demonstrated at the cell wall of the gram positive bacteria $C$. perfringens encased in either gelatin

or agarose, exposed for $30 \mathrm{~min}$, to reaction conditions prior to fixation and resin embedding by either standard fixation and processing $(\mathrm{A})$ or by microwave-assisted immunofixation $(\mathrm{B}),\left(\mathrm{OsO}_{4}\right.$ post fixed, UA/LC stained). Acid phosphatase activity was also apparent as dark rings of precipitate at the cell walls, (and particulate wicked off of the samples at end of reaction), when thin sections of microwave-assisted immunofixed colonies of this organism were assayed at room temperature (10 $\min )(\mathrm{E} \& \mathrm{~F})$, as compared to sections reacted with substrate and no capture agent $(\mathrm{C})$, or capture agent (lead) and no substrate (D). Bars (white): A, C, D, E, $500 \mathrm{~nm} ; \mathrm{B}, 200 \mathrm{~nm}$; and F, $1 \mu \mathrm{m}$. 